\title{
A Subutilização Da Dimensão Social Da Sustentabiliade Nos Processos Licitatórios E As Suas Consequências
}

\author{
Adriano Barbosa Mendonça * \\ Universiadade Federal do Rio Grande, Programa de Pós-Graduação em Direito e Justiça Social, Rio \\ Grande-RS, Brasil. \\ iD https://orcid.org/0000-0002-1433-2554 \\ Liane Francisca Hüning Pazinato** \\ Universiadade Federal do Rio Grande, Programa de Pós-Graduação em Direito e Justiça Social, Rio \\ Grande-RS, Brasil. \\ https://orcid.org/oooo-0002-7831-8815
}

Resumo: O presente trabalho tem como objetivo geral demonstrar que a dimensão social nos processos licitatórios gerenciados pelos órgãos e entidades que compõem a Administração Pública brasileira é subutilizada. Para tanto, buscou-se a origem do conceito de desenvolvimento sustentável, desde seu debate inicial nas Nações Unidas até a sua emergência no sistema normativo brasileiro. A partir desse recorte, num segundo momento, projetou-se ênfase à dimensão social para se concluir, ao fim, que esta não se efetiva visto que, embora legalmente prevista, na maioria das vezes é apenas o aspecto pecuniário do menor preço que prevalece. $\mathrm{O}$ método utilizado foi o dedutivo, partindo do conceito genérico do desenvolvimento sustentável, passando por suas dimensões, para se demonstrar especificamente que a dimensão social é subutilizada nos processos licitatórios. Utilizou-se pesquisa bibliográfica e jurisprudencial.

Palavras-chave: Licitação Sustentável, Sustentabilidade Multidimensional, Dimensão Social da Sustentabilidade.

* Mestrando do Programa de Pós-graduação em Direito e Justiça Social da Universidade Federal do Rio Grande (FURG). Assistente em administração do Instituto Federal de Educação, Ciência e Tecnologia do Rio Grande do Sul. E-mail: adriano.mendonca@riogrande.ifrs.edu.br

** Doutora em Direito pela Pontifícia Universidade Católica do Rio Grande do Sul - PUCRS. Professora permanente nos cursos de graduação e mestrado em Direito da Universidade Federal do Rio Grande FURG. E-mail: lianehuning@gmail.com

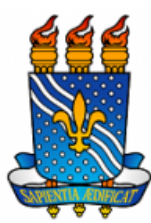

UNIVERSIDADE FEDERAL DA PARAÍBA

Programa de Pós-Graduação em Ciências Jurídicas

DOI: https://doi.org/10.22478/ufpb.1678-2593.2021v20n44.49281 


\title{
A Subutilização Da Dimensão Social Da Sustentabiliade Nos Processos Licitatórios E As Suas Consequências
}

\author{
Adriano Barbosa Mendonça
}

Liane Francisca Hüning Pazinato

\section{INTRODUÇÃO}

Busca-se com o presente artigo demonstrar que a dimensão social nos processos licitatórios gerenciados pelos órgãos e entidades que compõem a Administração Pública brasileira é subutilizada. Realidade esta que desconsidera seus impactos positivos ao desenvolvimento econômico sustentável nacional.

A pesquisa se justifica pela crescente conscientização de que os ciclos de produção e consumo produzem impactos sociais e ambientais, sendo relevante o papel que a Administração Pública ocupa quando ela é inserida nesse contexto consumerista.

O Tribunal de Contas da União (TCU), em 2017, identificou que apenas $1 \%$ do montante de aquisições e contratações públicas, em âmbito federal, é considerada sustentável. Tal indicativo corrobora a pessoal percepção de que os aspectos eminentemente pecuniários se sobrepõem aos benefícios multidimensionais da sustentabilidade.

Nesse sentido, o problema a ser respondido na presente pesquisa é o de verificar se a dimensão social é utilizada adequadamente nos processos licitatórios gerenciados pelos órgãos e entidades que compõem a Administração Pública brasileira. Analisando sob tal perspectiva, se apresentará um breve panorama das licitações sustentáveis. Sem a pretensão de ser exaustivo, busca-se 
apontar as origens da temática, bem como, sua perspectiva legal após a vigência da Lei $\mathrm{n}^{0}$ 12.349, de 15 de dezembro de 2010. Para tanto, dividir-se-á em três tópicos iniciais.

$\mathrm{Na}$ primeira parte denominada “origens da busca pelo desenvolvimento sustentável: dos debates iniciais até a sua emergência no sistema normativo brasileiro", serão delineadas, através de indicações bibliográficas, quais as circunstâncias da origem do desenvolvimento sustentável. Nesse contexto, serão destacadas cronologicamente as principais conferências acerca do desenvolvimento sustentável promovidas pela Organização das Nações Unidas (ONU), a fim de que se desenhe melhor o panorama internacional dispensado a temática, sendo analisadas quais foram suas consequências no plano constitucional brasileiro.

Em momento posterior, no segundo tópico, denominado "desenvolvimento sustentável como finalidade da licitação: breves considerações”, a pesquisa acadêmico-jurídica será estreitada para que, ao fim, seja conceituada a licitação sustentável. Aqui, serão destacadas suas potencialidades, bem como, seu tratamento normativo, através da analise de diversos autores administrativistas brasileiros.

O terceiro momento denominado "a dimensão social do desenvolvimento sustentável: oportunidades desperdiçadas”, tratará da sustentabilidade como princípio a ser explorado nas aquisições e contratações administrativas. Através do referencial teórico abordado será possível estabelecer que o desenvolvimento sustentável é um poder-dever, mesmo que isso possa refletir em custos financeiros maiores à Administração Pública. Considerando que a sustentabilidade é um princípio multidimensional, neste tópico, afunilando-se a temática, será abordada a dimensão social da sustentabilidade à luz do Decreto no 8.538, de 06 de outubro de 2015.

Por fim, concluir-se-á que o princípio do desenvolvimento sustentável, quanto sua dimensão social, não é explorado. Dessa forma, o objetivo geral será o de demonstrar que a dimensão social da 
sustentabilidade nos processos licitatórios gerenciados pelos órgãos e entidades que compõem a Administração Pública brasileira é subutilizada. O problema de sua subutilização é o da perda dos benefícios ligados à promoção da dimensão social da sustentabilidade, a saber: geração de empregos à população local, fortalecendo os micro e pequenos empreendedores; redução de custos com logística nas aquisições e prestação de serviços; aumento das receita dos municípios e região, resultando numa melhor prestação de serviços públicos, entre outros reflexos benéficos que reduzem as desigualdades sociais e regionais por intermédio das licitações sustentáveis.

Para tanto, como objetivos específicos, buscar-se-á a origem do desenvolvimento sustentável desde seu debate na ONU até seu despontar no sistema normativo brasileiro.

O método utilizado será o dedutivo partindo do conceito genérico do desenvolvimento sustentável, perpassando por suas dimensões para se demonstrar que a dimensão social não é observada nos processos licitatórios. A pesquisa será bibliográfica e jurisprudencial.

Por fim, convém salientar que a presente pesquisa se constitui como aposta eminentemente conceitual, cujo ulterior desenvolvimento empírico mostra-se relevante e necessário, pois se trata de um esforço em identificar na legislação e literatura administrativista nacional uma oportunidade para os gestores públicos implementarem uma agenda sustentável multidimensional no âmbito licitatório.

\section{ORIGENS DA BUSCA PELO DESENVOLVIMENTO SUSTENTÁVEL: DOS DEBATES INICIAIS ATÉ A SUA EMERGÊNCIA NO SISTEMA NORMATIVO BRASILEIRO}

O progresso técnico e científico do contexto globalizado modificou significativamente a estrutura das relações sociais 
contemporâneas. Diminuímos distâncias, pois a comunicação entre indivíduos é instantânea e alheia a limites geopolíticos o que, consequentemente, oportuniza a emergência de um canal democraticamente privilegiado; o melhoramento genético de espécies vegetais e animais artificialmente induzido pelo homem desafia a lógica darwiniana clássica da evolução e do dogmatismo religioso, mesmo que ainda desconhecidos seus efeitos em longo prazo, além dos avanços da medicina que possibilitam a subsistência humana longeva e com uma qualidade certamente não experimentada em momentos passados.

Esses singelos exemplos nos permitem evidenciar a radical maneira com que nossa sociedade atual domina o meio que a circunda e avoca para si a condução de nosso destino. Apesar desse contexto pressupor um progresso socialmente equilibrado, tal raciocínio é ingênuo ao desconsiderar que a relação entre o homem e o meio ambiente se encontra insustentavelmente abusiva ${ }_{1}$

Nessa perspectiva, pesquisadores alertam que o desenvolvimento se desloca num sentido diametralmente oposto aquele próspero cenário proporcionado pelos avanços técnicos e científicos. Trata-se do perecimento humano decorrente do esgotamento ambiental propiciado pelo modelo de produção e consumo atual. Compartilhando tal prognóstico, Juarez Freitas adverte-nos que se trata:

[...] da primeira vez na história, salvo risco de guerra nuclear, que a humanidade simplesmente pode inviabilizar sua permanência na Terra, por obra e desgraça, em larga escala, do seu estilo devorante, compulsivo e pouco amigável (2012, p. 24).

${ }^{1}$ Um interessante levantamento promovido pela organização internacional de pesquisa chamada Global Footprint Network - estima anualmente a demanda humana por recursos naturais e a correspondente capacidade regenerativa do meio ambiente. Segundo o grupo, em 2019, a data de 29 de julho foi o simbólico dia em que ficamos em débito com o meio ambiente. Analisando sua retrospectiva, constatase que no transcorrer dos anos o nosso "endividamento" é cada vez mais precoce (Global Footprint Network, 2019) 
As catástrofes ambientais transcendem os limites de soberania dos Estados, cujo território e povo ficam à mercê dos efeitos danosos causados, não raras vezes, por longínquas e complexas redes de desiquilíbrio socioambiental. Diante dessa axiomática necessidade de cooperação e solidariedade entre os Estados-nação, no avanço dos anos, diversos compromissos foram sendo assumidos perante a comunidade internacional com vistas a implementar uma agenda política una e pautada na busca de um direito ao futuro.

Do conjunto de pactos firmados entre Estados-nação, sem dúvidas, recebem maior destaque na agenda política internacional, as Conferências promovidas pela Organização das Nações Unidas (ONU). Restringindo-se a temática do desenvolvimento, Silva, Cabral e Giesta-Cabral afirmam que a "primeira grande conferência-marco na área do meio ambiente foi a Conferência de Estocolmo, em 1972. Nela está lançado o marco jurídico global para o equilíbrio entre economia e sustentabilidade" (2018, p. 2740).

Outros importantes eventos se sucederam após Estocolmo até que em 1987, categoricamente adota-se a definição do desenvolvimento sustentável ${ }^{2}$. Essa concepção veio com a publicação do documento "Nosso Futuro Comum" ou, como também ficou conhecido, Relatório Brundtland divulgado pela Comissão Mundial sobre o Meio Ambiente e o Desenvolvimento (CMMAD) da ONU que inaugura o conceito de desenvolvimento sustentável como aquele que "atende as necessidades do presente sem comprometer a possibilidade de as gerações futuras atenderem a suas próprias necessidades" (1991, p. 46). Apresentando de forma sintética as conclusões da CMMAD, Souza e Armada revelam que "o Relatório Brundtland considerou a

2 O conceito está longe de ser unânime entre pesquisadores. A título exemplificativo, o professor Juarez Freitas entende ser mais apropriado utilizar o vocábulo "sustentabilidade" a "desenvolvimento sustentável". Para tanto, argumenta que "a sustentabilidade é que deve adjetivar, condicionar e infundir as suas características ao desenvolvimento nunca ao contrário (2012, p. 54). Não pode ser ardilosamente esvaziada pelo crescimento econômico descriterioso e agressivo. Por isso, prefere-se falar em sustentabilidade (FREITAS, 2012, p. 54). Apesar de haver uma pluralidade de perspectivas, o presente trabalho não fará distinção entre "sustentabilidade" e "desenvolvimento sustentável" haja vista tal discussão ser indiferente a proposta aqui apresentada. 
possibilidade de alterações nos ecossistemas a partir do crescimento econômico" (2018, p. 28).

Dos eventos seminais realizados nas décadas de 70 e 80, sucederam-se diversas outras Convenções no âmbito da ONU cuja temática a respeito do Desenvolvimento Sustentável (DS) protagonizou e orientou os trabalhos. São elas: a Conferência das Nações Unidas sobre o Meio Ambiente e o Desenvolvimento, em 1992, no Rio de Janeiro; a Cúpula Mundial sobre Desenvolvimento Sustentável, em 2002, na cidade de Johanesburgo e a Cúpula das Nações Unidas sobre o Desenvolvimento Sustentável, em 2015, na cidade de Nova York.

Neste último encontro foi pactuado um compromisso político internacional onde 193 líderes de diversas nações, inclusive a brasileira, se comprometeram a cumprir dezessete Objetivos do Desenvolvimento Sustentável (ODS) para o ano de 20303. A respeito de seu conteúdo, Silva, Cabral e Giesta-Cabral registram que "através das metas nela traçadas, busca-se um desenvolvimento sustentável tanto na perspectiva ambiental quanto humana, de modo a conciliar progresso econômico, redução da pobreza e sustentabilidade” (2018, p. 2741).

O legado proporcionado por tais compromissos é inquestionável quando nos deparamos com seus reflexos sendo difundidos no plano interno dos países signatários. Pode-se afirmar, em termos diversos, que a incorporação legislativa do conceito de desenvolvimento sustentável traduz-se em uma nova compreensão da sistemática legal. Nesse sentido, Juarez Freitas destaca a sustentabilidade na hermenêutica constitucional brasileira:

[...] do entrelaçamento tópico-sistemático de dispositivos constitucionais, notadamente dos arts. $3^{\circ}, 170$, VI e 225 , avulta o critério da sustentabilidade (valor desdobrado em princípio), que intenta o desenvolvimento continuado e durável, socialmente redutor de iniquidades, voltado para presentes e futuras gerações, sem endossar o crescimento econômico irracional, aético, cruel e mefistofélico (2012, p. 112)

3 Para detalhes dos objetivos e metas ver a Agenda 2030 da ONU. Disponível em: < https://nacoesunidas.org/pos2015/agenda2030/>. Acesso em 19. fev. 2020. 
O desenvolvimento, portanto, é um conceito complexo que compreende a dimensão econômica de forma integrada aos aspectos e limites socioambientais. Nesse ponto, Teixeira e Costa observam que não é só uma "questão do Estado como política, mas também uma questão de sociedade. O Estado aparece como extensão social, e os titulares dos direitos ambientais e culturais são os cidadãos” (2017, p. 152).

A tutela do meio ambiente, portanto, representa um exercício de cidadania, cuja finalidade é a preservação de um meio ambiente sustentável garantido tanto para as presentes como para as futuras gerações. Não por acaso, o art. 225 da Constituição Federal tem redação coincidente com as conclusões do Relatório Brundtland ao prescrever que todos têm direito a um meio ambiente saudável “impondo-se ao Poder Público e à coletividade o dever de defendê-lo e preservá-lo para as presentes e futuras gerações” (Brasil, 1988).

Delimitados minimamente os contornos teóricos do conceito de desenvolvimento sustentável no contexto político internacional e do plano constitucional brasileiro, passamos a análise das políticas públicas de promoção da sustentabilidade na legislação infraconstitucional.

\section{DESENVOLVIMENTO SUSTENTÁVEL COMO FINALIDADE DA LICITAÇÃO: BREVES CONSIDERAÇÕES}

No tópico anterior foi delineada a proteção do meio ambiente com o Estado figurando como agente regulador do desenvolvimento. Agora, parte-se para a possibilidade de uma intervenção estatal diretamente no domínio econômico através de sua efetiva participação no ciclo de consumo e produção.

Quando analisamos o Estado consumidor, sob a perspectiva dos recursos públicos destinados à manutenção de despesas de subsistência da máquina administrativa, constatamos uma vultosa 
quantia de valores sendo reintroduzidas na economia. Segundo o portal da transparência do governo federal, no ano de 2018 a ordem de $\mathrm{R} \$ 73.746 .393 .824,46$ (aproximadamente $\mathrm{R} \$ 73,75$ bilhões) foi destinada ao pagamento dos fornecedores do Estado (Brasil, 2019)4. A subsistência da máquina administrativa, portanto, promove uma importante forma de redistribuição de receitas. Além dos aspectos pecuniários, convém destacar a posição privilegiada que o Estado consumidor detém e o seu potencial de alterar padrões de produção e consumo por intermédio das aquisições e contratações administrativas.

Marçal Justen Filho registra que "não é casual, por isso, que na maior parte dos países a disciplina das contratações administrativas incorpore regras destinadas a assegurar a realização de fins políticos de grande relevo" (2011, p. 12).

Diferentemente de uma organização da iniciativa privada, os entes e órgãos que compõem a Administração Pública estão adstritos a uma sucessão de atos pré-determinados na legislação, sendo bastante limitada a discricionariedade administrativa na definição de quem irá fornecer itens e serviços a ela. Defendendo a imparcialidade gerada pela sistemática normativa, Carvalho entende que:

A administração pública possui a tarefa árdua e complexa de manter o equilíbrio social e gerir a máquina pública. Por essa razão, não poderia a lei deixar a critério do administrador a escolha das pessoas a serem contratadas, porque essa liberdade daria margem a escolhas impróprias e escusas, desvirtuadas do interesse coletivo (2015, p. 429).

Em contraponto, Motta (2010) observa que a vinculação de atos imposta pela sistemática normativa é ilusória e "eventual sacrifício da eficiência/eficácia em nome do combate à corrupção, não

4 Vale destacar que o expressivo valor se encontra moderado. A Emenda Constitucional (EC) $\mathrm{n}^{\circ}$ 95, de 15 de dezembro de 2016, impôs limites ao orçamento público. Nos termos da EC, os vinte exercícios financeiros seguintes, a partir de 2018 , serão limitados ao valor do limite referente ao exercício imediatamente anterior, corrigido pela variação do Índice Nacional de Preços ao Consumidor Amplo - IPCA ou outro índice que venha a substituí-lo, para o período de doze meses encerrado em junho do exercício anterior a que se refere a lei orçamentária (BRASIL, 2016). 
vem surtindo os efeitos esperados" (apud Chaves, Bertassi e Silva, 2019, p. 85).

Esses procedimentos administrativos previamente estabelecidos na legislação para a seleção dos fornecedores estatais formam o complexo processo denominado licitação. Para Fernanda Marinela e Rogério Cunha, a licitação:

[...] é um procedimento administrativo destinado à seleção da melhor proposta dentre as apresentadas por aqueles que desejam contratar com a Administração Pública. Esse instrumento estriba-se na ideia de competição a ser travada, isonomicamente, entre os que preenchem os atributos e as aptidões necessários ao bom cumprimento das obrigações que se propõem assumir (2021, p. 49).

No mesmo sentido, segundo Maria Sylvia Zanella Di Pietro a licitação é a forma com que "a Administração abre a todos os interessados que se sujeitem às condições fixadas no instrumento convocatório, a possibilidade de apresentação de proposta” (2016, p. 412).

A licitação tem seu fundamento na Constituição Federal, disposta no art. 37, XXI, sendo de cunho obrigatório, como destaca José dos Santos Carvalho Filho "fora dos casos expressos em lei, as obras, serviços, compras e alienações serão contratados mediante processo de licitação pública que assegure igualdade de condições a todos os concorrentes” ${ }_{5}$ (2018, cap. 6).

Em linhas gerais, pode-se conceituar a licitação como um processo no qual uma demanda da Administração surge e fornecedores do ramo interessados oferecem suas propostas. Além de rituais pré-estabelecidos, quando analisamos a lei que regulamenta o dispositivo constitucional, a Lei $n^{0}$ 8.666, de 21 de junho de 1993,

5 Como bem observado, o dever de licitar não é absoluto. As hipóteses dos arts. 24 e 25 da Lei no 8.666, de 21 de junho de 1993, respectivamente, hipóteses de dispensa e inexigibilidade de licitação, são exemplos onde o gestor público está legitimado também a dispensar os processos licitatórios. Mesmo nesses casos, cumpre salientar, que tais exemplos são exceções taxativas e de interpretação restritiva. A respeito, José dos Santos Carvalho Filho defende que "não pode a Administração abdicar do certame licitatório antes da celebração de seus contratos, salvo em situações excepcionais definidas em lei” (2018, cap. 6). 
constatamos princípios e finalidades à licitação muito maiores que uma simples relação consumerista.

Nessa lei, o legislador ordinário preestabeleceu normas gerais visando a proteção do erário quando a Administração Pública figura na posição de consumidora, onde o tratamento isonômico dispensado aos interessados em provê-la, naturalmente pela sua competitividade, proporcionaria uma proposta mais economicamente vantajosa às suas aquisições. Apesar da louvável precaução do legislador, a atenção exclusivamente delimitada aos aspectos pecuniários das aquisições já não se mostra mais suficiente em tempos atuais, tendo em vista a progressiva conscientização que os recursos naturais são limitados e que o consumo produz impactos ambientais e sociais.

Tal concepção, inclusive, motivou a renovação da Lei Geral de Licitações, que incluiu em suas finalidades a promoção do desenvolvimento nacional sustentável, ao lado da isonomia e proposta mais vantajosa à Administração, conforme a exposição de motivos da MP 495/2010 esclarece

[...] impõe-se a necessidade de adoção de medidas que agreguem ao perfil de demanda do setor público diretrizes claras atinentes ao papel do Estado na promoção do desenvolvimento econômico e fortalecimento de cadeias produtivas de bens e serviços domésticos. Nesse contexto, torna-se particularmente relevante a atuação privilegiada do setor público com vistas à instituição de incentivos à pesquisa e à inovação que, reconhecidamente, consubstanciam poderoso efeito indutor ao desenvolvimento do país (BRASIL, 2010b).

A inovação proposta com a vigência da Lei $n^{0}$ 12.349, de 15 de dezembro de 2010, compatibiliza dimensões da licitação que outrora aparentavam ser conflitantes: a econômica e ambiental6. Scatolino e Trindade entendem que a alteração proposta tem "uma inclinação

${ }^{6}$ Nos termos do art. $3^{\text {o }}$ da Lei 8.666/93: "A licitação destina-se a garantir a observância do princípio constitucional da isonomia, a seleção da proposta mais vantajosa para a administração e a promoção do desenvolvimento nacional sustentável e será processada e julgada em estrita conformidade com os princípios básicos da legalidade, da impessoalidade, da moralidade, da igualdade, da publicidade, da probidade administrativa, da vinculação ao instrumento convocatório, do julgamento objetivo e dos que lhes são correlatos". (BRASIL, 1993) (grifo nosso) 
voltada, principalmente, para aspectos ambientais nele, também, deve ser incluído todos os aspectos que envolvem uma licitação como, por exemplo, questões de ordem econômica e desenvolvimentos regionais" (2016, p. 526).

A partir da leitura sistematizada da legislação, Rafael Carvalho Rezende Oliveira define a licitação como:

[...] processo administrativo utilizado pela Administração Pública e pelas demais pessoas indicadas pela lei, com o objetivo de garantir a isonomia, selecionar a melhor proposta e promover o desenvolvimento nacional sustentável, por meio de critérios objetivos e impessoais, para celebração de contratos (2018, cap. 1 ).

Quanto à representatividade do marco normativo, Grando e Bona registram que "tal princípio já estaria implícito na Constituição Federal de 1988, além de outros dispositivos legais, a exemplo da Lei n. ${ }^{\circ} 6.983$ de 31 de agosto 1981, que dispõe sobre a Política Nacional de Meio Ambiente" (2018, p. 30).

Destacado o marco que introduz uma nova perspectiva nos processos licitatórios, convém, agora, conceituar o que vem a ser efetivamente uma licitação sustentável.

Segundo Juarez Freitas, as licitações sustentáveis são aquelas que com “isonomia, visam à seleção de proposta mais vantajosa para a Administração Pública, ponderados com a máxima objetividade possível, os custos e benefícios, diretos e indiretos, sociais, econômicos e ambientais" (2012, p. 257).

No mesmo sentido, Victor Aguiar Jardim de Amorim entende que por "ostensiva imposição legal, deve a Administração realizar licitações sustentáveis, como forma de implementar contratos administrativos com cláusulas de sustentabilidade de cunho ambiental, econômico, social e cultural” (2017, p. 22).

Segundo o órgão jurídico consultivo da União, a AdvocaciaGeral da União (AGU), a licitação sustentável é a que:

[...] integra considerações socioambientais em todas as suas fases com o objetivo de reduzir impactos negativos sobre o meio ambiente e, via de consequência, aos direitos humanos. Trata-se de uma expressão abrangente, uma vez que não está delimitada pelo procedimento licitatório em 
si, mas perpassa todas as fases da contratação pública, desde o planejamento até a fiscalização da execução dos contratos (2016, p. 12-13).

Vale destacar que a perspectiva contida no trabalho referencial divulgado pela AGU considera a licitação sustentável uma importante ferramenta de concretização dos direitos humanos. Não obstante, Marçal Justen Filho aponta que processo licitatório possui fins maiores que a mera aquisição ou contratação em si considerada:

\begin{abstract}
Isso significa consagrar uma função regulatória adicional para a licitação e a contratação administrativa. Não se trata apenas de obter a contratação econômica e tecnicamente mais vantajosa, mas também de aproveitar a oportunidade da contratação para fomentar o desenvolvimento nacional sustentável. A contratação administrativa passou a ser concebida como um instrumento para a realização de outros fins, além da promoção de compras, serviços e alienações (2016, p. $548)$.
\end{abstract}

O conceito de sustentabilidade, portanto, é multidimensional. Desde a sua concepção na década de 80, novas dimensões foram sendo incorporadas. Reativas as novas demandas do desenvolvimento contemporâneo, onde novas formas de exclusão são inauguradas. De fato, o tripé (econômico, social e ambiental) da sustentabilidade já não se mostra mais suficiente frente aos desafios que enfrentamos e iremos enfrentar. Propostas revisionais não são escassas. A título exemplificativo, Juarez Freitas entende que existem cinco dimensões, sendo elas: ética, jurídico-política, ambiental, social e econômica (2012, p. 71).

Sendo tão plural o conceito de sustentabilidade, a presente pesquisa abordará exclusivamente a dimensão social, analisando especificamente no tópico seguinte se a legislação está cumprindo com a proposta de promover o desenvolvimento sustentável, especificamente, em sua dimensão social. 


\section{A DIMENSÃO SOCIAL DO DESENVOLVIMENTO SUSTENTÁVEL: OPORTUNIDADES DESPERDIÇADAS}

A promoção da sustentabilidade é perceptível em diversos processos licitatórios. Quanto à dimensão social, recente exemplo pode ser destacado como o Decreto $\mathrm{n}^{0}$ 9.5450/2018 que disciplina a obrigatoriedade de contratação de mão de obra egressa do sistema carcerário. A respeito dessas políticas, Juarez Freitas defende que:

[...] válidas são apenas as distinções voltadas a auxiliar os desfavorecidos, mediante ações positivas e compensações que permitam fazer frente à pobreza medida por padrões confiáveis, que levam em conta necessariamente a gravidade das questões ambientais (2012, p. 58).

De relevante importância para o estudo proposto, a vigência do Decreto $\mathrm{n}^{0}$ 8.538/2015, de 6 de outubro de 2015, oportunizou, dentre um rol expressivo de benefícios, uma reserva de mercado importante às Microempresas (ME) e Empresas de Pequeno Porte (EPP) no fornecimento de bens e prestação de serviços condicionado ao limite da despesa anual de $\mathrm{R} \$ 80.000,00$ (oitenta mil reais).

Apesar dessa reserva de mercado ao pequeno empreendedor representar um benefício aos comerciantes locais, Bertassi, Chaves e Silva (2019) demonstraram que os dados empíricos em muito se distanciam dessa realidade. Segundo os autores, no período pesquisado de três anos, num determinado órgão federal, a representatividade de empresas pertencentes à microrregião ${ }^{7}$ de estudo contratadas como fornecedoras do Estado é incipiente.

Os dados levantados nos indicam que, sob a perspectiva regional, a contribuição ao desenvolvimento local propiciado pela redistribuição de receitas públicas não é explorado. Apesar da viabilidade de encararmos o desenvolvimento regional como uma dimensão social da sustentabilidade, Bertassi, Chaves e Silva destacam

7 Segundo o Instituto Brasileiro de Geografia e Estatística (IBGE), microrregião é conceituada como a região composta de municípios limítrofes à localidade da sede da universidade investigada (BERTASSI; CHAVES; SILVA, 2019, p. 93). 
a tentativa de alteração da Lei $n^{0} 8.666 / 93$, frustrada sob o argumento de violação à competitividade e isonomia:

[...] o projeto foi rejeitado e arquivado, com a justificativa de que seu teor é contrário ao disposto no inciso I do $\S 1^{\circ}$ do art. $3^{\circ}$ da mesma Lei, o qual veda "cláusulas ou condições que comprometam, restrinjam ou frustrem o seu caráter competitivo, e estabeleçam preferências ou distinções em razão da naturalidade, da sede ou domicílio dos licitantes ou de qualquer outra circunstância" (2019, p. 95).

Constitucionalmente inoportuna. Nesse ponto, convém destacar o entendimento de Canotilho et. al. o qual entende que "a redução das desigualdades regionais é imperativo que deve permear todas a políticas públicas propostas e executadas no Brasil” (2013, p. 149).

O problema da subutilização da sustentabilidade social é a da perda dos benefícios ligados à promoção da dimensão social da sustentabilidade, a saber: geração de empregos à população local, fortalecendo os micro e pequenos empreendedores; reduz custo de logística nas aquisições e prestação de serviços; aumenta a receita dos municípios próximos, resultando numa melhor prestação de serviços públicos, entre outros reflexos benéficos que reduzem as desigualdades sociais e regionais por intermédio das licitações sustentáveis.

$\mathrm{Na}$ perspectiva de Di Pietro “o princípio da licitação sustentável autoriza a previsão, nos instrumentos convocatórios, de exigências que podem ser vistas como discriminatórias, mas que se harmonizam com o princípio da isonomia" (2016, p. 431). Ainda quanto à isonomia, lembra Rafael Carvalho Rezende Oliveira que “pressupõe, por vezes, tratamento desigual entre as pessoas que não se encontram na mesma situação fático-jurídica (tratamento desigual aos desiguais), desde que respeitado o princípio da proporcionalidade" (2016, cap. 1). Em próximo sentido, Medauar assinala que a própria Lei 8.666/93 e outras leis "fixam ressalvas à igualdade de tratamento 
dos licitantes, seja mediante margens de preferência, seja quanto à restrição a tipos de bens e serviços objeto da licitação” (2015, p. 178)

Essa perspectiva de restringir o benefício das licitações sustentáveis sob o argumento de uma possível violação a isonomia é incorrer na valoração demasiada de um princípio em detrimento de outro. A respeito da necessidade de harmonia na interpretação do sistema normativo, Fernanda Marinela coloca que:

Reconhecida a força coercitiva dos princípios que regem o ordenamento jurídico, considerando a importância enquanto mola propulsora para as demais regras do sistema, a inobservância a um princípio gera uma ofensa a todo o sistema de comandos, e não somente a um mandamento obrigatório específico. Essa desatenção é a forma mais grave de ilegalidade ou inconstitucionalidade, porque representa uma agressão contra todo o sistema, uma violação dos valores fundamentais, gerando uma corrosão de sua estrutura mestra (2018, cap. 2).

O que se busca com as licitações sustentáveis é a proposta mais vantajosa à Administração, ponderando-se os princípios e finalidades licitatórias. Seu objetivo não se limita a aspectos pecuniários. Nesse sentido, Marçal Justen Filho observa que:

[...] o critério do menor preço pode ser acompanhado da avaliação da vantajosidade sob o prisma do desenvolvimento nacional. Portanto, surge a possibilidade de sagrar-se vencedora uma proposta de valor mais elevado, desde que se evidencie ser ela mais adequada para promover o desenvolvimento nacional sustentável (2016, p. 549).

Logicamente não se está defendendo a utilização do desenvolvimento sustentável como justificativa para lançamento de despesas incoerentes com a sistemática legal. A respeito, Marçal Justen Filho conclui que é “indispensável a existência de regras precisas e exatas, definindo concretamente os critérios de apuração da vantagem relacionada ao desenvolvimento nacional sustentável” (2016, p. 549).

Esse é o posicionamento, inclusive, manifestado pelo Tribunal de Contas da União (TCU) no Acórdão no 1.375/2015:

É legítimo que as contratações da Administração Pública se adequem a novos parâmetros de sustentabilidade ambiental, ainda que com possíveis reflexos na 
economicidade da contratação. Deve constar expressamente dos processos de licitação motivação fundamentada que justifique a definição das exigências de caráter ambiental, as quais devem incidir sobre o objeto a ser contratado e não como critério de habilitação da empresa licitante (Brasil, 2015).

Mesmo existindo marcos teóricos e normativos legítimos a induzir o gestor público a promover o desenvolvimento sustentável através das licitações, estudos como Bertassi, Chaves e Silva (2019) evidenciam que a sustentabilidade é um conceito não praticado. A respeito, Coutinho registra que:

[...] gestores públicos, juristas ou não, temem que as razões práticas e funcionais que dão para justificar essa ou aquela medida sejam questionadas por órgãos de controle, como os tribunais de contas" (2013, p. 188).

Essa suposta precaução, no entanto, não é motivação suficiente para que a legislação não seja cumprida. Nesse sentido, Juarez Freitas defende uma releitura do direito administrativo que "nesse embate, não resta lugar para abstenção: opta-se pelo Direito Administrativo da sustentabilidade" (2012, p. 199).

Não se trata, portanto, de opção do gestor público. Como anteriormente exposto, a sustentabilidade é um princípio e como tal deve ser obrigatoriamente encarado. A respeito, Fernanda Marinela alerta-nos que na inobservância e no "desrespeito a um princípio, também há a possibilidade de aplicação da Lei n. 8.429/92, reconhecendo-se a conduta como ato de improbidade administrativa, previsto no art. 11 do citado diploma" (2018, cap. 2).

Assim, o propósito das licitações sustentáveis é aproveitar o poder de compra do setor público quando este adquire bens ou contrata serviços. Assumido como princípio, o desenvolvimento sustentável deve obrigatoriamente ser explorado, inclusive, sob pena de sua inobservância resultar em violação a legislação e, consequentemente, responsabilização administrativa dos agentes infratores. 
Cabe, por fim, destacar o papel do direito que além de fornecer segurança jurídica aos gestores públicos, tem o condão de propor mudanças quando os termos legais não encontram respaldo empírico como no caso do estudo de Bertassi, Chaves e Silva (2019). Segundo Coutinho, o direito deve ser entendido "também como regras internas que permitem a calibragem e autocorreção operacional" (2013, p. 197).

Assim, propõe-se a efetivação do princípio do desenvolvimento sustentável, pois cada processo licitatório sem sua observação, além de ser uma ilegalidade, projeta um futuro incerto e que se afasta dos ideais de justiça social insculpidos, inclusive, na ordem constitucional.

\section{CONCLUSÃo}

Para verificar o problema proposto, a subutilização da sustentabilidade social nos processos licitatórios, percorreu-se três etapas. Primeiramente, para fins de compreensão de sua origem, foi abordada a evolução do conceito de desenvolvimento sustentável, a partir das Conferências da Organização das Nações Unidas, a fim de que se desenhe melhor o panorama internacional dispensado a temática. A partir disto, foram analisadas suas consequências no plano constitucional brasileiro com a finalidade de reverter o quadro de autofagia ambiental que sociedade contemporânea construiu.

Em um segundo momento, passou-se a análise do processo formal que os órgãos e entidades que compõem a Administração Pública valem-se para satisfação de suas necessidades de consumo: a licitação. Nesse tópico, buscou-se o tratamento dispensado pelo sistema normativo ao processo licitatório, abordando suas finalidades e princípios de forma sistemática, destacando suas potencialidades em razão da dimensão de recursos envolvidos nas contratações administrativas. Assim, foi conceituada a licitação sustentável e o seu caráter multidimensional.

Em um terceiro momento, finalmente, foi analisado o poderdever do desenvolvimento sustentável nas licitações, mesmo que isso 
possa refletir em custos financeiros maiores à Administração Pública. Afunilando-se a temática, foi abordada a dimensão social da sustentabilidade à luz do Decreto $\mathrm{n}^{0}$ 8.538, de 06 de outubro de 2015, para ao fim, concluir-se que o princípio do desenvolvimento sustentável, na dimensão social, não é explorado, utilizando-se além da bibliografia consultada, o estudo empreendido por Bertassi, Chaves e Silva (2019) que chegou a entendimento semelhante.

Em termos de conclusão geral, destaca-se que o conceito de sustentabilidade deve ser encarado como um princípio que deve ser contemplado nas aquisições administrativas, sob pena de responsabilização direta do agente público e indireta à sociedade em geral que não usufrui da justiça social proporcionada pelo seu cumprimento, concluindo-se na subutilização da sustentabilidade social por processos licitatórios.

Nesta senda, recomenda-se que os gestores públicos, explorem mais a dimensão social da sustentabilidade, através do fomento a empresas locais, tendo em vista que não existe hierarquia entre os princípios previstos na Lei 8.666/93, estimulando assim um maior desenvolvimento econômico regional.

Data de Submissão: 22/11/2019

Data de Aprovação: 04/03/2020

Processo de Avaliação: double blind peer review

Editor Geral: Jailton Macena de Araújo

Editor de Área: Jailton Macena de Araújo

Assistente Editorial: Jaqueline Rosário Santana

\section{REFERÊNCIAS}

AMORIM, Victor Aguiar Jardim de. Licitações e Contratos Administrativos: Teoria e Jurisprudência. Brasília: Editora do Senado Federal, 2017. 
BRASIL. Advocacia-Geral da União (AGU). Consultoria - Geral da União. Guia Nacional de Licitações Sustentáveis. Brasília: AGU, 2016.

BRASIL. Câmara dos deputados. Exposição de motivos da MP no 495/2010. Brasília, 2010b. Disponível em:

http://www.planalto.gov.br/ccivil_03/_ato2007-

2010/2010/Exm/EMI-104-MP-MF-MEC-MCT-MPV-495-10.htm. Acesso em: 26 jul. 2019.

BRASIL. Constituição Federal de 1988. Promulgada em 5 de outubro de 1988. Disponível em

http://www.planalto.gov.br/ccivil_03/constituicao/constituição.htm . Acesso em: 24 ago. 2019.

BRASIL. Decreto no 8.538, de 6 de outubro de 2015.

Regulamenta o tratamento favorecido, diferenciado e simplificado para as microempresas, empresas de pequeno porte, agricultores familiares, produtores rurais pessoa física e outros. Brasília: 2015. Disponível em: http://www.planalto.gov.br/ccivil_03/_ato20152018/2015/decreto/d8538.htm. Acesso em: 24 ago. 2019.

BRASIL. Decreto no 9.450, de 24 de julho de 2018 . Institui a Política Nacional de Trabalho no âmbito do Sistema Prisional, voltada à ampliação e qualificação da oferta de vagas de trabalho, ao empreendedorismo e à formação profissional das pessoas presas e egressas do sistema prisional, e regulamenta o $\S 5^{\circ}$ do art. 40 da Lei no 8.666, de 21 de junho de 1993, que regulamenta o disposto no inciso XXI do caput do art. 37 da Constituição e institui normas para licitações e contratos da administração pública firmados pelo Poder Executivo federal. Brasília: 2018. Casa Civil. Disponível em: http://www.planalto.gov.br/ccivil_03/_ato20152018/2018/decreto/D9450.htm. Acesso em: 25 ago. 2019.

BRASIL. Emenda Constitucional no 95, de 15 de dezembro de 2016. Altera o Ato das Disposições Constitucionais Transitórias para instituir o Novo Regime Fiscal e dá outras providências. Brasília: 2016. Disponível em http://www.planalto.gov.br/ccivil_o3/constituicao/Emendas/Emc/e mc95.htm. Acesso em: 24 ago. 2019.

BRASIL. Lei no . 8.666, de 21 de junho de 1993. Regulamenta o art. 37, inciso XXI, da Constituição Federal, institui normas para licitações e contratos da Administração Pública e dá outras providências. Brasília: 1993. Disponível em: http:// www.planalto.gov.br/ccivil_o3/Leis/L8666cons.htm. Acesso em: 24 ago. 2019. 
BRASIL. Lei no. 12.349, de 15 de dezembro de 2010. Altera as Leis nos 8.666, de 21 de junho de 1993, 8.958, de 20 de dezembro de 1994, e 10.973, de 2 de dezembro de 2004; e revoga o § 10 do art. 20 da Lei no 11.273, de 6 de fevereiro de 2006. Brasília: 2010a. http://www.planalto.gov.br/ccivil_03/_ato20072010/2010/lei/l12349.htm Acesso em: 24 ago. 2019.

BRASIL. Portal da Transparência Governo Federal. 2019. Disponível em: http://www.portaltransparencia.gov.br/licitacoes?ano=2018. Acesso em: 25 ago. 2019.

BRASIL. Tribunal de Contas da União. Acórdão n. 1.375/2015 Plenário. Relator: Min. Bruno Dantas. [S.1.: s.n.], 2015b. Disponível em:

https://contas.tcu.gov.br/sagas/SvlVisualizarRelVotoAcRtf?codFiltr $\mathrm{o}=$ SAGAS-SESSAOENCERRADA\&-

seOcultaPagina $=\mathrm{S} \&$ itemo=524298. Acesso em: 24 ago. 2019.

BRASIL. TRIBUNAL DE CONTAS DA UNIÃO (TCU). Acórdão no 1056/2017 - Plenário - Processo no TC oo6.615/2016-3. Relator Ministro-Substituto André Luís de Carvalho. Data da Sessão: 24/5/2017. Disponível em:

https://contas.tcu.gov.br/sagas/SvlVisualizarRelVotoAcRtf?codFiltr $\mathrm{o}=$ SAGAS-SESSAO-

ENCERRADA\&seOcultaPagina $=S \& i t e m o=586451$. Acesso em: $18 \mathrm{fev}$. 2020.

CANOTILHO, José Gomes; MENDES, Gilmar Ferreira; SARLET Ingo Wolfgang; STRECK, Lenio. Comentários à Constituição do Brasil. São Paulo: Saraiva Educação, 2013.

CARVAlHO FILHO, José dos Santos. Manual de Direito Administrativo. 31. ed. São Paulo: Atlas, 2018. E-book (não paginado).

CARVALHO, Matheus. Manual de Direito Administrativo. 2. ed. Salvador. Juspodivm, 2015.

CHAVES, Fernanda Rodrigues Drumond; BERTASSI, André Luís; SILVA, Gustavo Melo. Compras Públicas e Desenvolvimento Local: Micro e Pequenas Empresas Locais nas Licitações de uma Universidade Pública Mineira. Revista de Empreendedorismo e Gestão de Pequenas Empresas, v. 8, n. 1, p. 77-101, jan. 2019. Disponível em: https://www.regepe.org.br/regepe/article/view/867. Acesso em: 26 ago. 2019. 
COUTINHO, Diogo Rosenthal. O direito nas políticas públicas. In: A política pública como campo multidisciplinar [S.l: s.n.], p. 282, 2013.

CMMAD. Comissão Mundial sobre Meio Ambiente e Desenvolvimento. Nosso futuro comum. 2. ed. Tradução da Editora da FGV de Our common future. Rio de Janeiro: Editora da Fundação Getúlio Vargas, 1991.

DI PIETRO, Maria Sylvia Zanella. Direito Administrativo. 29. ed. Rio de Janeiro: Forense, 2016.

GLOBAL FOOTPRINT NETWORK. National Footprint Accounts. 2019. Disponível em: https://www.overshootday.org/newsroom/past-earth-overshootdays. Acesso em: 24.ago. 2019.

GRANDO, Fabiane; BONA, Celito de. $O$ aspecto jurídico da sustentabilidade - instrumentos normativos regulamentadores das licitações sustentáveis. Revista de Direito e Sustentabilidade. v. 4, n. 2. p. 20 - 39. Porto Alegre, 2018. Disponível em: https://bit.ly/2xkEgZT. Acesso em 23 ago. 2019.

FREITAS, Juarez. Sustentabilidade: direito ao futuro. 2. ed. Belo Horizonte: Fórum, 2012.

JUSTEN FILHO, Marçal. Comentários à lei de licitações e contratos administrativos. 12. ed. São Paulo: Dialética, 2011.

JUSTEN FILHO, Marçal. Curso de Direito Administrativo. 12. ed. São Paulo: Revista dos Tribunais, 2016.

MARINELA, Fernanda. Direito Administrativo. 12. ed. São Paulo: Saraiva Educação, 2018. E-book (não paginado).

MARINELA, Fernanda. CUNHA, Rogério Sanches. Manual de licitações e contratos administrativos. Ed. $1^{\text {a }}$. Salvador: JusPodivm, 2021.

MEDAUAR, Odete. Direito administrativo moderno. 19. ed. São Paulo: Revista dos Tribunais, 2015.

NAÇÕES UNIDAS NO BRASIL. ONU BR. A Agenda 2030. Disponível em: https://nacoesunidas.org/pos2015/agenda2030/. Acesso em: 19 fev. 2020.

OLIVEIRA, Rafael Carvalho Rezende. Curso de Direito Administrativo. 4. ed. São Paulo: Método, 2018. E-book (não paginado). 
A Subutilização Da Dimensão Social Da Sustentabiliade Nos Processos...

SCATOLINO, Gustavo; TRINDADE, João. Manual de Direito

Administrativo. 4. ed. Salvador: Juspodivm, 2016.

SILVA, Carlucio Germano da; CABRAL, Rafael Lamera Giesta; GIESTA-CABRAL, Lílian Caporlíngua. Promoção de desenvolvimento sustentável no nível municipal: uma análise da dispensa de licitação na coleta seletiva de resíduos frente a agenda 2030. Revista de Direito da Cidade, [S.l.], v. 10, n. 4, p. 2736-2769, dez. 2018. ISSN 2317-7721. Disponível em: https://www.e-

publicacoes.uerj.br/index.php/rdc/article/view/34702/27232.

Acesso em: 24 ago. 2019.

SOUZA, Maria Claudia Da Silva Antunes de; ARMADA, Charles

Alexandre Souza. Desenvolvimento sustentável e sustentabilidade: evolução epistemológica na necessária diferenciação entre os conceitos. In: Maria Cláudia da Silva Antunes de Souza; Charles Alexandre Souza Armada. (org.).

Sustentabilidade: um olhar multidimensional e contemporâneo. Itajái: UNIVALI, 2018, v. 01, p. 26-42. Disponível em: https://bit.ly/2vG7jqs. Acesso em: 24 ago. 2019.

TEIXEIRA. Angélica Cristiny Ezequiel de Avelar, COSTA. Beatriz Souza. Sociedades tradicionais, desenvolvimento econômico e meio ambiente: reflexões para a sustentabilidade como valor constitucional. Revista Direito Ambiental e Sociedade, v. 7, n. 2, p. 145-167, 2018. Disponível em: <http://www.ucs.br/etc/revistas/index.php/direitoambiental/article /view/3956/3094>. Acesso em: 24 ago. 2019. 


\title{
The Underutilization of the social dimension of sustainability in bidding processes and its consequences
}

\author{
Adriano Barbosa Mendonça
}

\author{
Liane Francisca Hüning Pazinato
}

\begin{abstract}
The present work has as general objective to demonstrate that the social dimension in the bidding processes managed by the organs and entities that make up the Brazilian Public Administration is underutilized. To this end, we sought the origin of the concept of sustainable development, from its initial debate at the United Nations to its emergence in the Brazilian regulatory system. From this perspective, in a second moment, emphasis was projected to the social dimension to conclude, in the end, that this does not take place since, although legally foreseen, in most cases it is only the pecuniary aspect of the lowest price that prevails. The method used was the deductive one, starting from the generic concept of sustainable development, passing through its dimensions, to demonstrate specifically that the social dimension is underused in bidding processes. Bibliographic and jurisprudential research was used.
\end{abstract}

Keywords: Sustainable Bidding. Multidimensional Sustainability. Social Dimension of Sustainability.

DOI: https://doi.org/10.22478/ufpb.1678-2593.2021v2on44.49281

Conteúdo sob licença Creative Commons: Attribuition-NonCommercial-NoDerivative 4.o International (CC BY-NC-ND 4.0) 